\title{
Bio-inspired chemical hydrogen storage and discharge as a source of electrical energy
}

\author{
Fabian Fischer $\cdot$ Sophie Mermoud • \\ Gnagna Diouf · Christèle Bastian
}

Received: 23 February 2012/Accepted: 9 April 2012/Published online: 22 April 2012

(C) Springer Science+Business Media B.V. 2012

\begin{abstract}
Reversible bio-inspired chemical hydrogen storage systems accumulate electrical energy in the form of electrons and proton ions located on biomolecules or bio-like storage molecules. Electro-active biomolecules (EAB) in Yeast media show such behavior: $2 \mathrm{e}^{-}+$ $2 \mathrm{H}^{+}+\mathrm{EAB}_{(\mathrm{aq})}^{+} \leftrightarrows \mathrm{EABH} / \mathrm{H}_{(\mathrm{aq})}^{+}$, also electro-active Methylene Blue (MB): $2 \mathrm{e}^{-}+2 \mathrm{H}^{+}+\mathrm{MB}_{\text {(aq) }}^{+} \leftrightarrows \mathrm{MBH} / \mathrm{H}_{(\mathrm{aq})}^{+}$. The power characteristics of microbial fuel cell stacks equipped with such bio-inspired hydrogen storage systems were examined. E. coli cultures charged these bio-inspired separate chemical hydrogen storage units up to $E=0.50 \pm 0.06 \mathrm{~V}$; cell potentials increased proportionally in serial double, triple, and quadruple hydrogen storage stacks up to $E_{\mathrm{OCV}}=1.98 \mathrm{~V}$; the maximum power densities that were obtained improved proportionally with stack length by an increment of 1.4. The bio-inspired chemical hydrogen storage principle is of great interest for application in low-cost batteries that store renewable energy.
\end{abstract}

Keywords Microbial fuel cell · Stack · Bioelectricity · Energy storage $\cdot$ Current loss

\section{Introduction}

Microbial fuel cells (MFC) are living hydrogen storage systems, in which reduced nicotinamide adenine dinucleotide (NADH), flavin adenine dinucleotide (FAD), ubiquinone and other electro-active biomolecules (EAB)

F. Fischer $(\bowtie) \cdot$ S. Mermoud · G. Diouf · C. Bastian Institute of Life Technologies, HES-SO Valais, University of Applied Sciences Western Switzerland, Route du Rawyl 64, 1950 Sion, Switzerland

e-mail: Fabian.fischer@hevs.ch intermittently accumulate proton ions and electrons as hydrogen equivalents, Eq. 1. This principle can be expanded by enriching MFC-cultures with electron/proton ion carriers [1]. MB is one of the mediators used for this purpose [2]. Separate MB-based aqueous chemical hydrogen storage systems can be used to store MFC-energy in a biosimilar manner. The use of commercial capacitors for electricity storage is another option that has explored for single MFC [3, 4], but their functionality is different, as they do not store proton ions. The storage systems described in this paper are therefore not capacitors [5], but chemical hydrogen storages. The mediator MB was added to the integrated hydrogen storage cell for proton ion and electron storage in stoichiometric quantities. This type of reversible bio-inspired non-biotic hydrogen storage is closely related to the chemical hydrogen storage principle [6-8]. In conclusion, bio-inspired chemical hydrogen storage is a bionic variant of the hydrogen storage principle found in all kinds of living cells.

$2 \mathrm{e}^{-}+2 \mathrm{H}^{+}+\mathrm{EAB}_{(\mathrm{aq})}^{+} \leftrightarrows \mathrm{EABH} / \mathrm{H}_{(\mathrm{aq})}^{+}$

Microbial fuel cell stacks supply higher working power than single units $[9,10]$; for that reason they can overcome the notoriously low power characteristics of single MFC. Through the linking of single MFCs to serial stacks, the voltage increases by $\sim 0.5 \mathrm{~V}$ per stack unit. However, microbial activity varies between single MFC and cell potentials and currents may be inverted [11]. Continuous flow through stacks is a means to insure unidirectional current flows providing homogenous microbial activity in all anode half-cells. The constant circulation of the culture through larger stacks requires mechanical energy and limits the efficiency. In the study presented here, we investigated the possibility of using MFC stacks as a source of scalable power. Such reversible bio-inspired hydrogen storage 
systems could be used as non-biotic batteries to store energy during low-demand periods. It is a cost-effective alternative to thermodynamically non-spontaneous hydrogen gas production by electrolysis and subsequent gas storage, as these steps are not needed in biosimilar hydrogen storage. This principle allows the storage of renewable energy produced by MFC; it can also be applied to solar, wind, and wave energy if electrical energy is to be transformed into electrons and proton ions.

\section{Materials and methods}

\subsection{Materials}

Escherichia coli K12/ATCC 23716/DSM 498 from Sigma Aldrich [Steinheim, Germany] were used in all cultures. Tryptic Soy Broth (TSB), Yeast extract, and Peptone Tryptic Digest of casein were from Biolife [Milano, Italy] and D-(+)glucose monohydrate from Brenntag Schweizerhall [Basel, Switzerland]. The MB from Fluka [Buchs, Switzerland] was prepared as a $0.5 \mathrm{mM}$ stock solution and stored at $4{ }^{\circ} \mathrm{C}$. Potassium hexacyanoferrate(III), $\mathrm{K}_{3} \mathrm{FeCN}_{6}$, sodium hydrogen phosphates $\left(\mathrm{NaH}_{2} \mathrm{PO}_{4}\right.$ and $\left.\mathrm{Na}_{2} \mathrm{HPO}_{4} \cdot 2 \mathrm{H}_{2} \mathrm{O}\right)$ and sodium hydrogen carbonate $\left(\mathrm{NaHCO}_{3}\right)$ were purchased from Sigma Aldrich [Steinheim, Germany].

\subsection{Microbial fuel cell construction}

Four MFC were constructed from Plexiglas and PVC (Fig. 1a-h). The central $500 \mathrm{~mL}$ compartment (c) served as

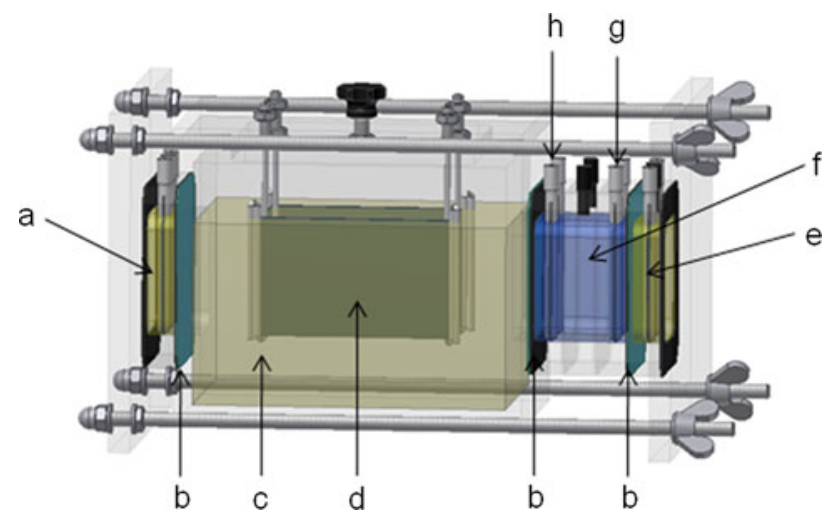

Fig. 1 Microbial fuel cell with an integrated bio-inspired hydrogen storage unit $(f)$, and a reference electrode $(a)$. Three proton exchange membranes $(b)$ separate the four half-cells $(a, c, f, e)$. The bioreactor compartment $(c)$ contains a large anode $(d)$ for harvesting electrons. The non-biotic hydrogen storage unit $(f)$ contains two electrodes: one for charging and discharging $(g)$, and a second one for monitoring the hydrogen storage potential $(h)$. The electrodes $(e)$ and $(g)$ are used to link several units and form stacks culture chamber. An adjacent $30 \mathrm{~mL}$ cell (f) was added as hydrogen storage unit. At opposite ends, two $10 \mathrm{~mL}$ cavities served as cathodes (a, e), one for discharging (e) and the other one for on-line monitoring (a) of the potential of the culture. All electrodes consisted of woven carbon tissue; the area of the anode in the culture chamber was $225 \mathrm{~cm}^{2}$ (d); the other electrodes in the hydrogen storage and the cathodes were $25 \mathrm{~cm}^{2}$ each (a, e). Two, three, and four single MFCs were linked together to form serial and parallel stacks (Fig. 2).

\subsection{Culture}

The culture media consisted of $5 \mathrm{~g}$ Yeast extract, $7.37 \mathrm{~g}$ $\mathrm{NaH}_{2} \mathrm{PO}_{4}$, and $10.00 \mathrm{~g} \mathrm{NaHCO}_{3}$ per litre of demineralized water and was subsequently homogenized and sterilized $\left(121^{\circ} \mathrm{C} / 15 \mathrm{~min}\right)$. An Escherichia coli K12 pre-culture with $50 \mathrm{~g}$ TSB was incubated $37^{\circ} \mathrm{C} / 48 \mathrm{~h}$ and inoculated to $500 \mathrm{~mL}$ media with $11 \mathrm{~g}$ glucose monohydrate, which was subsequently transferred to the MFC (Fig. 1c). After up to 2 days of acclimatization the cultivations produced bioelectricity.

\subsection{Hydrogen storage solution}

Solutions of $0.1-0.5 \mathrm{mM} \mathrm{MB}$ in $0.1 \mathrm{mM}$ phosphate buffer were poured in the $30 \mathrm{~mL}$ hydrogen storage cell (Fig. 1f). The cell contained two carbon-tissue electrodes $\left(25 \mathrm{~cm}^{2}\right.$ each) at a distance of $\sim 10 \mathrm{~mm}$, one for charging/

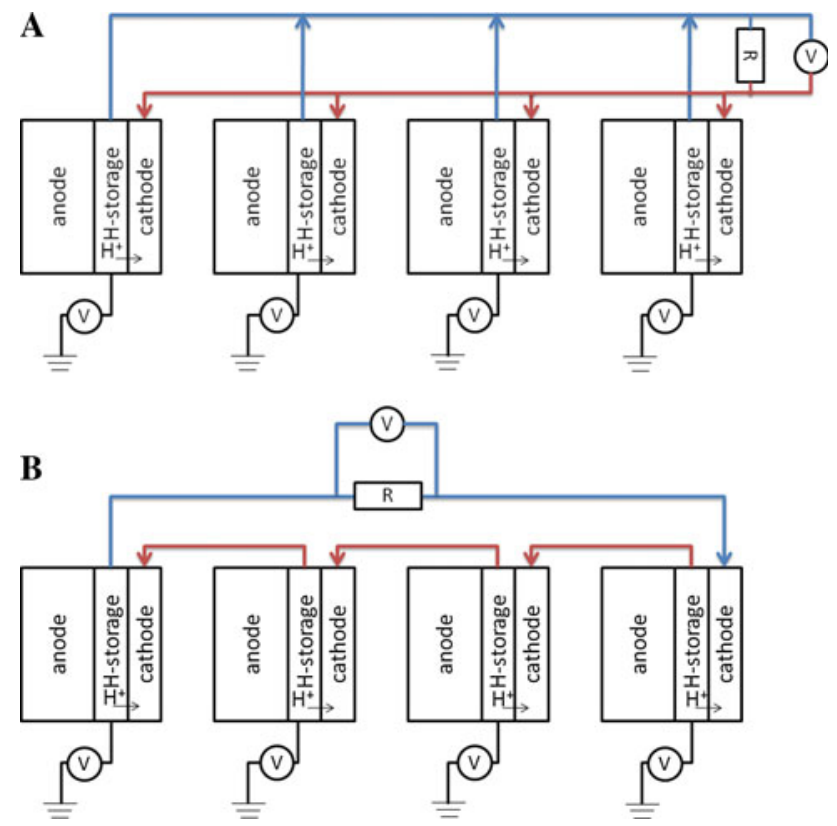

Fig. 2 Principle of parallel (a) and serial (b) bio-inspired hydrogen storage stacks while producing electricity 
discharging and the other one for monitoring the storage potential $E_{\mathrm{OCV}(\mathrm{H} \text {-storage) }}$.

\subsection{Stack characterization}

A series of 24 resistors $(100,000-100 \Omega)$ were used in the polarization experiments to record current densities and working potentials. The polarization sweeps were carried out with a 1 min waiting time for stabilization between resistor changes. The data series were used for drawing polarization curves and power-current plots, $P=I \times$ $E_{\mathrm{MFC}(\mathrm{stack})}$. Internal resistances $\left(R_{\mathrm{int}}\right.$ between hydrogen storage cell and cathode) were determined using Kirchhoff's law $\left(R_{\text {int }}=U / I\right)$ and from power maxima $\left(R_{\text {int }}=P_{\max } / I^{2}\right)$.

\section{Results and discussion}

\subsection{Bio-inspired hydrogen storage}

In order to demonstrate that the proposed hydrogen storage principle is bio-inspired, Yeast media was poured in a hydrogen storage cell and charged by the metabolic activity in the MFC anode. Power sweeps show that this non-biotic Yeast media stores electrons and proton ions as hydrogen equivalents (Table 1). MB in pure water and in culture media was charged in the same manner. Polarization indicates that $\mathrm{MB}$ stores electrons and proton ions as expected, and in combination with non-biotic culture media higher power maxima resulted.

From a bionic perspective mediators are to some extent artificial cofactors or electro-active species present in microbes and culture media. The redox properties of MB $\left(E_{\text {media }}^{\mathrm{o}}=-0.16 \mathrm{~V}\right)$ (Eq. 2) [1] are similar to those of

Table 1 Maximum power stored in non-biotic Yeast media, Methylene Blue, and Methylene Blue in culture media, employing the same chemical hydrogen storage unit size

\begin{tabular}{lccc}
\hline $\begin{array}{l}\text { Methylene } \\
\text { Blue }(\mathrm{mM})\end{array}$ & $\begin{array}{l}\text { Yeast extract } \\
\left(\mathrm{g} \mathrm{L}^{-1}\right)\end{array}$ & $\begin{array}{l}\text { Current density } \\
\left(\mu \mathrm{Am}^{-2}\right)\end{array}$ & $\begin{array}{l}\text { Max power } \\
(\mu \mathrm{W} \mathrm{cm})^{-2}\end{array}$ \\
\hline & 5 & 3.9 & 0.6 \\
& 10 & 9.7 & 1.6 \\
& 15 & 11.7 & 2.1 \\
0.2 & 20 & 16.2 & 3.2 \\
0.4 & & 11.8 & 4.5 \\
$0.2^{\mathrm{a}}$ & & 28.7 & 13.5 \\
$0.4^{\mathrm{a}}$ & & 12.6 & 5.4 \\
\hline
\end{tabular}

${ }^{\text {a }}$ With culture media

b At maximum power during polarization cofactors such as NADH $\left(E^{\circ}=-0.32 \mathrm{~V}\right)($ Eq. 3$)$ and FAD $\left(E^{\circ}=-0.20 \mathrm{~V}\right)$ (Eq. 4). Similar hydrogen storage properties have been found for other electro-active species in microbes and culture media. The most prominent in Yeast media is the cysteine redox couple: $\left(E^{\circ}=-0.22 \mathrm{~V}\right)$ (Eq. 5) [12]. Reduced cysteine thiols (CysSH) are known to transfer electrons [13] but the role in the hydrogen storage is not understood. Many other artificial mediators are known and are candidates for such bio-inspired hydrogen storage systems. The storage of electrons and proton ions in a 1:1 ratio, i.e., as ionized hydrogen, needs no additional energy for the formation of hydrogen gas and subsequent storage. In summary, bio-inspired hydrogen storage systems accumulate dissociated and ionized hydrogen and energy as $2 \mathrm{e}^{-}$and $2 \mathrm{H}^{+}$per mediator molecule, respectively.

$$
\begin{aligned}
& \mathrm{MB}^{+}+2 \mathrm{e}^{-}+2 \mathrm{H}^{+} \leftrightarrows \mathrm{MBH} / \mathrm{H}^{+} \\
& \mathrm{NAD}^{+}+2 \mathrm{e}^{-}+2 \mathrm{H}^{+} \leftrightarrows \mathrm{NADH} / \mathrm{H}^{+} \\
& \mathrm{FAD}+2 \mathrm{e}^{-}+2 \mathrm{H}^{+} \leftrightarrows \mathrm{FADH}_{2} \\
& \text { CysSSCys }+2 \mathrm{e}^{-}+2 \mathrm{H}^{+} \leftrightarrows 2 \mathrm{CysSH}
\end{aligned}
$$

3.2 Charging and discharging of the bio-inspired hydrogen storage system

Bio-inspired MB hydrogen storage systems easily accumulated energy up to a cell potential of $E_{\mathrm{OCV}(\mathrm{H}-\mathrm{Stor}-}$ age) $=0.5 \mathrm{~V}$. The operational cell potential $E_{\mathrm{OCV}}$ in aqueous solutions is known for aqueous capacitors to lie between 0 and $1.0 \mathrm{~V}$ [5]. In any case, the chemical hydrogen storage potential does not rise above the value of the corresponding charging culture, $E_{\text {culture }} \geq E_{\mathrm{H}-\text { Storage }} \sim$ $0.5 \mathrm{~V}$. Therefore, aqueous chemical hydrogen storage systems are ideal for biological working potentials (Fig. 3).

Two, three, and four MFC with integrated bio-inspired chemical hydrogen storage units arranged to stacks (Fig. 2) allowed the examination of their serial power characteristics. The standard electromotive force between MB and hexacyanoferrate(III) is $0.57 \mathrm{~V}$ (Eq. 6), while the fully charged storage system reached a maximum of $E_{\mathrm{OCV}(\mathrm{H}-}$ Storage) $=0.7 \mathrm{~V}$, as the cell potential of the used E. coli culture attained maximum values of $0.7-0.9 \mathrm{~V}$ against the hexacyanoferrate(III) cathode. In reality, the redox potentials of mediator molecules are not absolute and the standard potential of, e.g., MB depends on the environment [1].

$\Delta E_{\mathrm{OCV}, \mathrm{Fe}(\mathrm{CN})_{6}^{3-} / \mathrm{MB}}^{\mathrm{o}}=E_{\mathrm{Fe}(\mathrm{CN})_{6}^{3-} / \mathrm{Fe}(\mathrm{CN})_{6}^{4-}}^{\mathrm{o}}+E_{\mathrm{MB}_{\text {media }}}^{\mathrm{o}}$

The charging current density increased during the first $18 \mathrm{~h}$ and subsequently decreased to close to zero; a storage potential of $E_{\mathrm{OCV} \text { (H-Storage) }}=0.45-0.5 \mathrm{~V}$ (Fig. 4) was attained. Above $E_{\mathrm{H}-\text { Storage }}>0.5 \mathrm{~V}$, continued charging was slow, as the electromotive force between culture and 


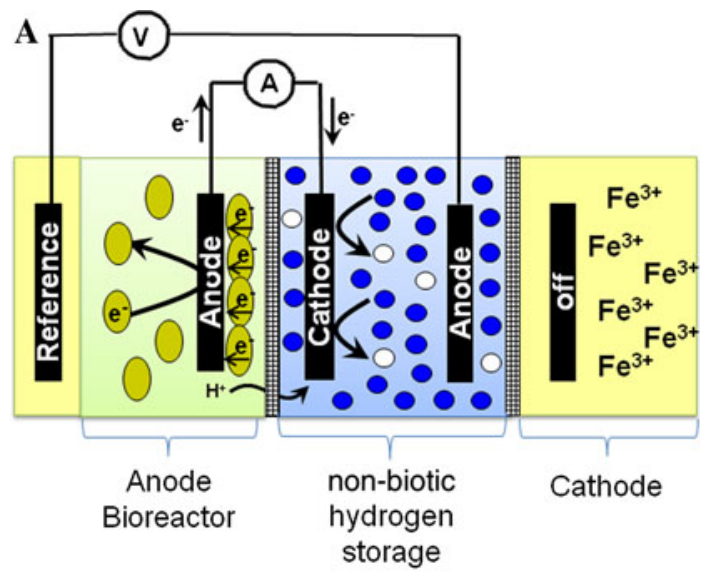

B
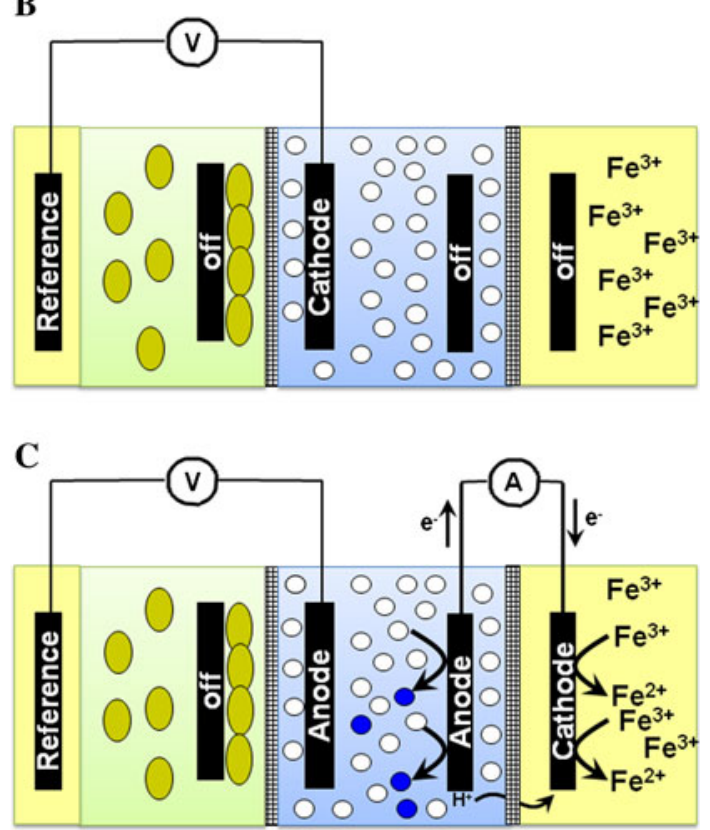

Fig. 3 Three functional modes for bio-inspired hydrogen storage systems and the redox reactions that take place in such systems: a Charging of a non-biotic hydrogen storage system by a microbial culture: energy $+2 \mathrm{e}^{-}+2 \mathrm{H}^{+}+\mathrm{MB}^{+} \rightarrow \mathrm{MBH} / \mathrm{H}^{+}$. b A fully charged storage becomes clear, power is stored as $\mathrm{MBH} / \mathrm{H}^{+}$. c The non-biotic storage system is discharged while producing electricity: $\mathrm{MBH} / \mathrm{H}^{+} \rightarrow 2 \mathrm{e}^{-}+2 \mathrm{H}^{+}+\mathrm{MB}^{+}+$energy

storage solution became smaller $\left(\Delta E_{\text {emf(final })} \sim 0.4 \mathrm{~V}\right)$. Once the storage solution reached $E_{\mathrm{OCV} \text { (H-Storage) }}>$ $0.45 \mathrm{~V}$, the MB solution turned clear (Eq. 2) (Fig. 3b). The blue color reappeared upon discharging (Fig. 3c), but a strong hysteresis effect kept the storage solution clear down to $E_{\mathrm{OCV} \text { (H-Storage) }}=0.2 \mathrm{~V}$. The persistent clarity indicates that $\mathrm{MB}$ remained partly reduced. The charge indicator properties of MB are therefore not useful and for that reason potentiometric on-line monitoring was usually carried out. Bio-inspired power storage systems are suitable for bioelectricity, as their cell potentials correspond to the working potentials of biological systems.

\subsection{Scalability of stacked bio-inspired hydrogen storage systems}

Microbial fuel cell stacks with integrated bio-inspired hydrogen storage units are suitable for scalable power generation. The open-circuit potential of serial storage stacks with two, three, and four units was $E_{(\mathrm{OCV})}=$ $1.10 \mathrm{~V}, 1.72 \mathrm{~V}$, respectively $1.98 \mathrm{~V}$, corresponding to multiples of the single-cell potential, $E_{(\mathrm{OCV}) \text { single }} \sim 0.50 \pm$ $0.06 \mathrm{~V}$, whereas the potential for parallel stacks remained unchanged at $E_{(\mathrm{OCV})} \sim 0.50 \mathrm{~V}$. Polarization curves and power-current density plots were recorded for serial and parallel MFC stacks (Fig. 5b, c). The power-current maxima of the polarization sweeps confirmed the scalability of serial stacks, whereas parallel stacks suffered from shortcircuiting losses. The maximum power $P_{\max }$ of the serial stacks increased by a factor of 1.4. With parallel stacks, the factor was smaller, only 0.9 .

The internal resistance $R_{\text {int }}$ of the MB storage stacks connected to the hexacyanoferrate(III) cathodes in the fuel cell stacks were calculated from the linear sections of the polarization curves $\left(U=R_{\text {int }} I\right)$ and compared to the resistance calculated from the power maxima $\left(P_{\max }=R_{\text {int }} /\right.$ $I^{2}$ ). Internal resistance increases with stack length, but each unit possesses a somewhat different internal resistance, as the distance between the carbon-tissue electrodes varied slightly. In conclusion, the number of MFCs in a serial stack correlates to an increase in internal resistance.

\subsection{Current loss during polarization}

Current losses occurred in the absence of any microbial activity. Power-current plots of single MFC often take the shape of atypical bent parabolas [14-17]. The phenomenon is also observed in microbial fuel cell stacks [11]. In some cases, current-power curves suddenly break down at maximum power; this phenomenon is known as power overshoot. This change is either permanent or the system returns to higher current at lower resistance. Current losses as found for the hydrogen storage systems in this study and for MFC in other papers are in some way related to the power overshoot. Several aspects of this phenomenon have been investigated. Some authors have examined whether mass transport limitations in microbial cultures provoke the power overshoot, but the phenomenon persists at higher stirring rates [18]. The power overshoot correlates also with increasing internal resistance, microbial exhaustion [19], and metabolic resistance in substrate conversion [20]. By controlling all these parameters, the power overshoot could be eliminated [21].

In this study, we distinguish between a power overshoot where the maximum current and power match, and the current loss that occurs after power maxima during 
Fig. 4 a Increase in non-biotic hydrogen storage potential during charging of $0.2,0.3$, and $0.5 \mathrm{mM}$ Methylene Blue solutions, and b corresponding current densities

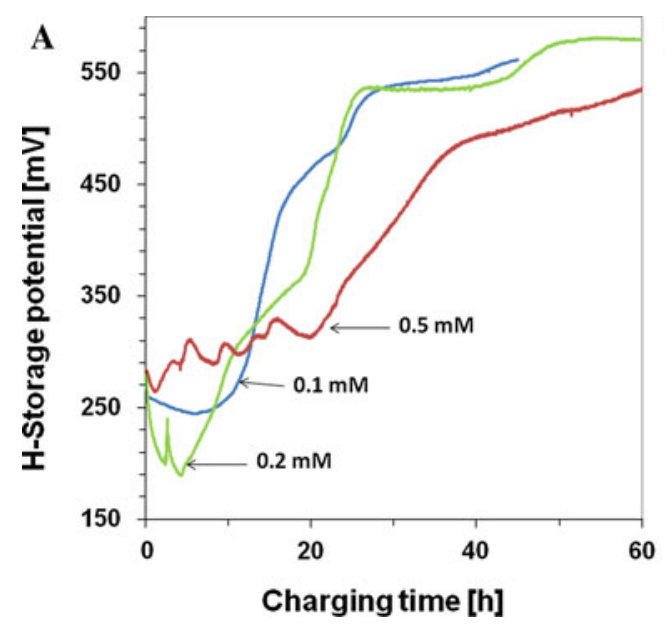

polarization experiments have been reached. In fact, current loss was observed in this study as an in-bent parabola when using MB hydrogen storage systems (Fig. 5a). The lower the MB concentration, the more pronounced the effect was. It is to be noted that the internal resistance increased with higher dilution $\left(R_{\mathrm{int}(0.5 \mathrm{M})}=4.0 \mathrm{k} \Omega\right.$ and $\left.R_{\text {int }(0.2 \mathrm{M})}=28 \mathrm{k} \Omega\right)$. This indicates that a quantitative electron transfer to the cathode triggers the current loss due to electron depletion.

Current losses also frequently occurred in serial MFC stacks using $0.5 \mathrm{mM} \mathrm{MB}$, but hardly in parallel arrangements (Fig. 5b, c). Current densities per non-biotic storage-unit increased with the length of serial stacks (Fig. 6), while in parallel stacks, the net current density decreased systematically. The highest current density per unit was observed with a serial quadruple stack, reaching $6.00 \mu \mathrm{A} \mathrm{cm} \mathrm{cm}^{-2}$ at 4,690 $\Omega$. The current density of the corresponding parallel stack resulted in the lowest current density observed, $0.85 \mu \mathrm{A} \mathrm{cm}{ }^{-2}$. In comparison, the single unit yielded $2.75 \mu \mathrm{A} \mathrm{cm}^{-2}$ (Fig. 6). The low currents in the parallel stack result from short-circuiting losses due to the relatively low internal resistance of the single units $\left(R_{\text {int(MFCsingle })}=4.0 \mathrm{k} \Omega\right)$. The incipient current loss in the parallel quadruple stack shows that short-circuiting losses do occur (Fig. 5c). In conclusion, the more efficient the MFC design, the more likely electron depletion will cause current losses during polarization.

\subsection{Potential rise during polarization}

Discharging the bio-inspired chemical hydrogen storage systems increased the cell potential in the storage system as a result of charge separation. Electrons flow faster through the external circuit than proton ions migrate in the proton exchange membrane. Therefore, the charge density $\left(a_{\mathrm{ox}}\right)$ in the MB solution remained high. The rise in cell potential $\Delta E_{\mathrm{OCV}(\mathrm{H}-\text { Storage) }}$ correlated with increasing current densities at resistances of $<50 \mathrm{k} \Omega$ for serial, and $<1 \mathrm{k} \Omega$ for parallel stacks (Fig. 6).
$E_{\mathrm{H}-\text { Storage }}=E_{\mathrm{MB}}^{\mathrm{o}}+\frac{R T}{z F} \ln \frac{a_{\mathrm{ox}}}{a_{\mathrm{red}}}$

Two positive charges per reduced Methylene Blue $\mathrm{MBH} / \mathrm{H}^{+}$unit are created upon oxidation (Eq. 2). Consequently, the proton ion density in the bio-inspired hydrogen storage system increases when the proton ion flux into the cathode is limited. This hypothesis was confirmed by an increase in cell potential of $\Delta E_{\mathrm{OCV}(\mathrm{H} \text {-Storage) }}$ of about $15 \mathrm{mV}$. Thus, the rising density of oxidized species $\left(a_{\mathrm{ox}}\right)$ increases the open-circuit cell potential $E_{\mathrm{H}-S t o r a g e}$. This can be explained using the Nernst Eq. 7 and represents a concentration-based potential increase. Nevertheless, even though the cell potential rose, the working potential per non-biotic storage-unit decreased with increasing stack size. Ultimately, the current loss is largely a phenomenon of electron depletion, and the sluggish proton ion migration in the proton exchange membrane is less important.

\subsection{Perspectives of bio-inspired hydrogen storage systems}

Bio-inspired chemical hydrogen storage systems are lowcost batteries for MFC power that can be generated when power demand is low. They also facilitate unidirectional current flow in mediator-free microbial fuel cell stacks and allow the scaling-up of microbial fuel cell stacks. Two features insure the scalability: (i) MFC stacks limit the dependency on ever changing microbial activity as they accumulate power when available. (ii) Serial hydrogen storage stacks deliver a higher power because individual cell potentials are additive. Potential inversion as experienced in uncontrolled mediator-free microbial fuel cell stacks cannot occur.

Another quality of the investigated power storage principle is the hydrogen storage function. The hydrogen is stored on mediators as dissociated and ionized bio-hydrogen (Eq. 8). Power storage systems are urgently needed in 

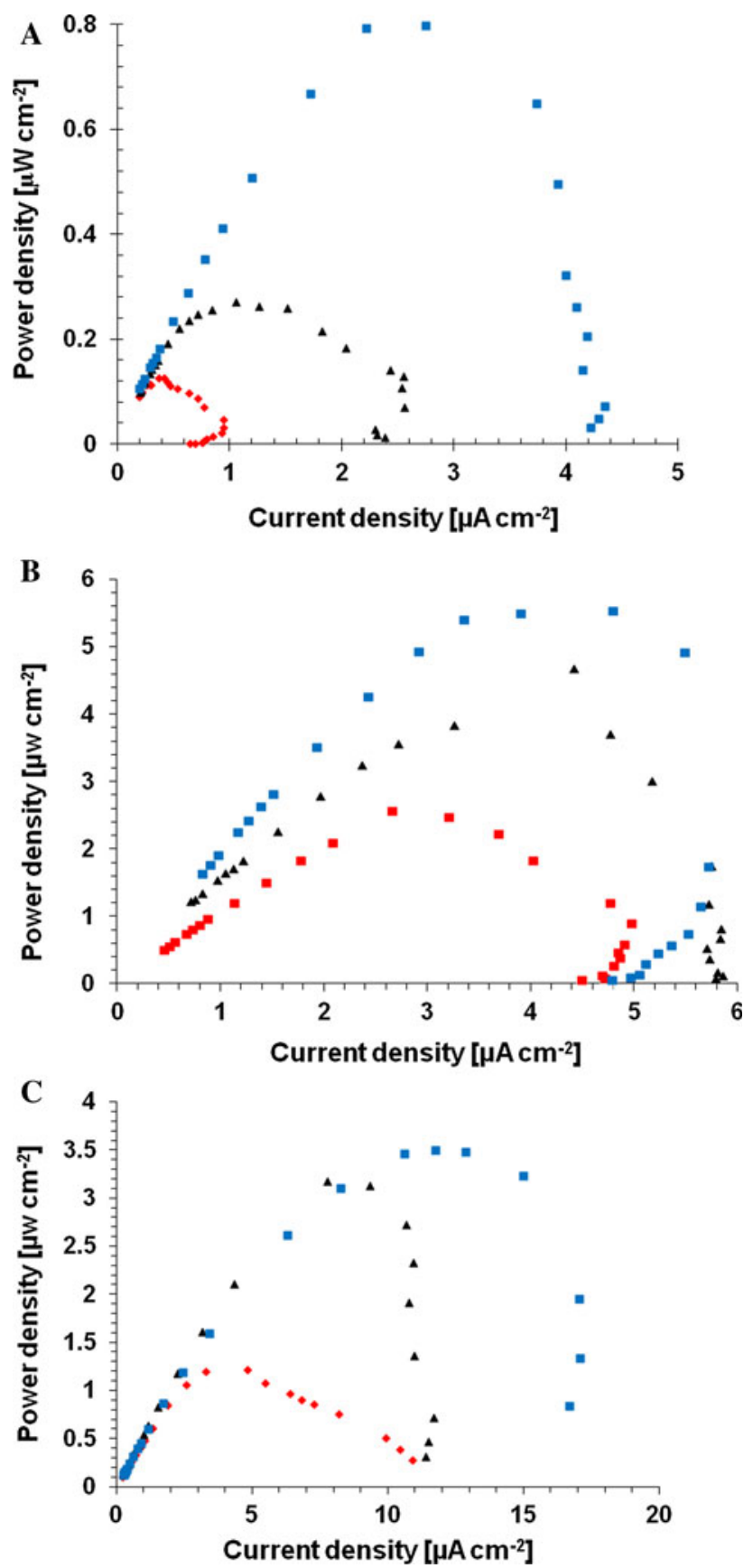

Fig. 5 a Single bio-inspired non-biotic hydrogen storage system with current loss visible as in-bent parabola caused by reduced 0.2 (filled diamond) and $0.3 \mathrm{mM}$ (filled square) Methylene Blue solutions, but not at a higher concentration of $0.5 \mathrm{mM}$ (filled triangle). b Powercurrent density plots for serial stacks of two (filled diamond), three (filled triangle) and four (filled square) bio-inspired hydrogen storage systems with $0.5 \mathrm{mM}$ Methylene Blue and $\mathbf{c}$ the parallel connection

renewable energy production to store off-peak energy from sources such as biomass and organic waste, as described in this study, wind, wave, or solar power. The technology for the transformation of such energy into electrons and proton ions is the only step to be added,

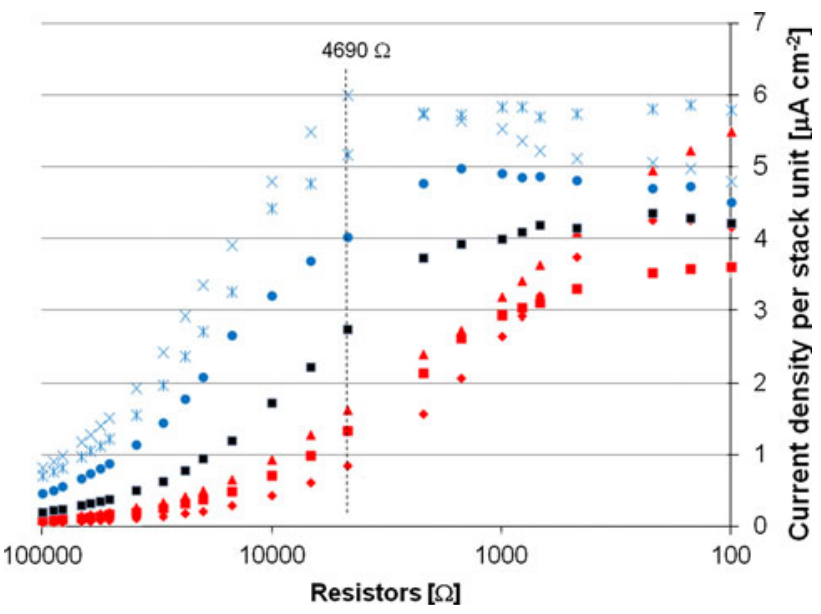

Fig. 6 Current densities during polarization sweeps with bio-inspired non-biotic hydrogen storage stacks normalized per single unit. In the middle, the single stack hydrogen storage curve (filled square) as reference value. In serial stacks, current densities increase from double (filled circle), to triple (asterisk) and quadruple (times) stacks. In parallel connection, net current densities decrease from double (filled triangle), to triple (filled square) and quadruple (filled diamond) stacks

which should consume less energy than the usual production of hydrogen gas by non-spontaneous electrolysis and energy-consuming gas storage. Contrary to modern efficient batteries, the used battery material is cheap and available. All in all, microbial fuel cell stacks with integrated aqueous chemical hydrogen storage units are models for scaled energy production from biomass and organic matter such as wastewater effluents.

Mediator $+2 \mathrm{e}^{-}+2 \mathrm{H}^{+} \leftrightarrows$ Mediator $-\mathrm{H}_{2}$

\section{Conclusions}

The use of bio-inspired non-biotic chemical hydrogen storage systems is potentially more efficient than the thermodynamically non-spontaneous electrolysis of hydrogen gas and subsequent storage. MFC with integrated bioinspired chemical hydrogen storage units store electrical power produced by MFC. Stacked MFC with chemical hydrogen storage units also improve controlled power production from biofuel cell stacks. The non-biotic hydrogen storage system, which represents a radically simplified MFC anolyte, unexpectedly revealed the cause for the frequently observed current loss during polarization experiments with MFC. This current loss is non-biotic and is caused by electron exhaustion. In final conclusion, bio-inspired chemical hydrogen storage systems efficiently store microbial fuel cell power; this fact is of the highest interest for other renewable power sources like solar, wind, and wave sources that typically produce off-peak energy. 


\section{References}

1. Sund CJ, McMasters S, Crittenden SR, Harrell LE, Sumner JJ (2007) Appl Microbiol Biotechnol 76:561

2. Bennetto HP (1990) Biotechnol Educ 1:163

3. Dewan A, Beyenal H, Lewandowski Z (2009) Environ Sci Technol 43:4600

4. Dewan A, Donovan C, Heo D, Beyenal H (2010) J Power Sources 195:90

5. Kötz R, Carlen M (2000) Electrochim Acta 45:2483

6. Churchard AJ, Banach E, Borgschulte A, Caputo R, Chen J-C, Clary D, Fijalkowski KJ, Geerlings H, Genova RV, Grochala W, Jaroń T, Juanes-Marcos JC, Kasemo B, Kroes GJ, Ljubić I, Naujoks N, Nørskov JK, Olsen RA, Pendolino F, Remhof A, Románszki L, Tekin A, Vegge T, Zäch M, Züttel A (2011) Phys Chem Chem Phys 13:16955 (2011)

7. Eberle U, Felderhoff M, Schüth F (2009) Angew Chem Int Ed 48:6608

8. Graetz J (2009) Chem Soc Rev 38:73
9. Liu Z, Liu J, Zhang S, Su Z (2008) Biotechnol Lett 30:1017

10. Ieropoulos I, Greenman J, Melhuish C (2008) Int J Energy Res 32:1228

11. Oh SE, Logan BE (2007) J Power Sources 167:11

12. Jocelyn PC (1967) Eur J Biochem 2:327

13. Doong RA, Schink B (2002) Environ Sci Technol 36:2939

14. Katuri KP, Scott K (2010) Biotechnol Bioeng 107:52

15. Martin E, Savadogo O, Guiot SR, Tartakovsky B (2010) Biochem Eng J 51:132

16. Pant D, Van Bogaert G, De Smet M, Diels L, Vanbroekhoven K (2010) Electrochim Acta 55:7710

17. Premiera GC, Kim JR, Michie I, Dinsdale RM, Guwy AJ (2011) J Power Sources 196:2013

18. Min B, Roman OB, Angelidaki I (2008) Biotechnol Lett 30:1213

19. Ieropoulos I, Winfield J, Greenman J (2010) Bioresour Technol 101:3520

20. Nien PC, Lee CY, Ho KC, Adav SS, Liu L, Wang A, Ren N, Lee DJ (2011) Bioresour Technol 102:4742

21. Watson VJ, Logan BE (2011) Electrochem Commun 13:54 